\title{
The influence of breed and environmental factors on social and solitary play in dogs (Canis lupus familiaris)
}

\author{
Lindsay R. Mehrkam ${ }^{1,3}$ • Nathaniel J. Hall ${ }^{2,3}$ - Chelsea Haitz ${ }^{3}$ Clive D. L. Wynne Cr,4 $^{3,4}$
}

Published online: 12 July 2017

(C) Psychonomic Society, Inc. 2017

\begin{abstract}
The domestic dog is an ideal model species in which to study the genetic and environmental factors that influence play behavior. Dogs exist in a wide variety of breeds and frequently engage in multiple forms of play. In the present study, we investigated whether the levels of solitary and social play differed between dogs of three breed types with distinct predatory motor pattern sequences (herding dogs, retrievers, and livestock guarding dogs [LGDs]). Furthermore, we investigated how environmental factors (social and nonsocial contexts) influenced play in dogs of these breed types. Groups of breed-matched dyads with working experience and of equivalent age, sex, and neuter status ratios were exposed to four experimental test conditions and two control conditions in randomized orders. With respect to solitary play, environmental context did have a significant effect, with toys reliably producing the highest levels of solitary play across all breed types. Retrievers engaged in significantly higher levels of solitary play overall than LGDs, and there was a trend in comparison to herding dogs. In contrast, neither environmental context nor breed had a significant effect on social play levels; however, neuter status of the dyads did have a significant effect on social play, with mixed-status dyads engaging in
\end{abstract}

Lindsay R. Mehrkam

lmehrkam@monmouth.edu

1 Department of Psychology, Monmouth University, 142 Howard Hall, West Long Branch, NJ 07764, USA

2 Department of Animal and Food Sciences, Texas Tech University, Lubbock, TX, USA

3 Department of Psychology, University of Florida, Gainesville, FL, USA

4 Department of Psychology, Arizona State University, Tempe, AZ, USA significantly higher levels of social play than same-status dyads. Our findings provide experimental evidence for identifying proximate, environmental stimuli that reliably facilitate social and solitary play and discuss possible genetic (i.e., breed type) and lifetime influences on the form of play in domestic dogs.

Keywords Social play $\cdot$ Solitary play $\cdot$ Dog $\cdot$ Breed . Predatory motor pattern $\cdot$ Environmental $\cdot$ Proximate mechanism $\cdot$ Toy $\cdot$ Attention

Once considered purposeless (de Haan, 1952), today, play is recognized as a social behavior of growing interest for scientific study. Play, however, is often characterized by its apparent lack of readily observable function, and defined as all activity that appears to an observer to have no immediate benefits for the performer but which involves motor patterns typical of functional contexts (i.e., agonistic, predatory or antipredatory, and sexual behavior; Bekoff, 2001; Martin \& Caro, 1985; Pellis \& Pellis, 1996). This is theoretically problematic since play can incur immediate costs to the participants, including an increased risk of injury and predation (Burghardt, 2005; Fagen, 1981; Harcourt, 1991), and loss of energy (Palagi, 2007). Thus, it follows that since play has costs, to be maintained in the population, it must also afford benefits (Bekoff \& Byers, 1998; Fagen, 1981; Hinde, 1974; P. K. Smith, 1982).

The lack of any obvious immediate benefits of play has led to an emphasis on long-term or ultimate functions of play rather than possible proximate causes during the lifetime of an individual (Bekoff \& Byers, 1998; Hall, 1998), although some studies have considered proximate factors in primates (Pellis \& Iwaniuk, 2004; Palagi, 2007), domestic cats (Hall \& Bradshaw, 1998), and rodents (e.g., Smith, Fantella, \& Pellis, 1999), particularly with respect to neurobehavioral 
mechanisms of social play in rats (e.g., Siviy, 2016; Vanderschuren, Acterberg, \& Trezza, 2016). Notwithstanding these exceptions, however, relatively few studies have attempted to study the potential proximate mechanisms of social play in a range of species, and only a subset of these provide experimental evidence of environmental causes of play specifically (e.g., Hall \& Bradshaw, 1998). This trend is problematic, given that a complete scientific understanding of any form of animal behavior must include an account of immediate benefits as well as delayed, cumulative consequences (Tinbergen, 1963).

Although in general, play behavior can be difficult to define, it is often structurally categorized as either locomotor play, social play, and object play, which are not necessarily mutually exclusive (e.g., locomotor play can be both social and solitary; social play may involve an object, conspecifics, or individuals of different species; and object play may also be either social or solitary). Social play is usually the most amenable form of play to study, since it is the most obvious and is generally performed more frequently and for longer periods than either object or solitary play in many species (Burghardt, 2005). Domestic dogs, however, will readily engage in both solitary and social object play and may thus be an ideal species in which to study both the proximate and genetic factors that underlie the different forms of play (Bradshaw, Pullen, \& Rooney, 2015). It is well established that play is most common in larger brained vertebrates (Burghardt, 2005; Pellis, \& Iwaniuk, 2004); in particular, domestic dogs (Canis lupus familiaris) have been identified as a readily accessible species with characteristically high levels of intraspecific play, even as adults (Bauer \& Smuts, 2007; Burghardt, 2005; Cordoni, 2009; Horowitz, 2009; Russell, 1936; Ward, Bauer, \& Smuts, 2008), and therefore offer an ideal model for continued examination of the elusive proximate mechanisms of this behavior.

Domestic dogs also represent an ideal model for examining possible genetic influences on behavior, given the large variety of distinct dog breeds today (Burghardt, Albright, \& Davis, 2016; Mehrkam \& Wynne, 2014). At present, however, the relative roles of breed-related and environmental factors in accounting for differences in play frequency and structure among domestic dogs have received little empirical attention until recently (Bradshaw et al., 2015). One recent exception, however, was shown by Burghardt et al. (2016) that found breed differences in object play in Vizslas. Standard Poodles, and Welsh Terriers when exposed to five standardized toys. Importantly, Burghardt and colleagues did not find hunger to be the dogs' primary motivation for engaging in object play, as predatory characteristics during object play occurred prior to the onset of weaning; this finding is in contrast to several previous studies that have reported a relationship between hunger or food deprivation and increased object play levels in domestic cats (Hall, 1998) among other species, such as primates (e.g., Pellis, 1991), though there are some exceptions (e.g., Ahloy Dallaire \& Mason, 2016).

Given that social play in canids contains actions that are used in predatory contexts (Bekoff, 1995; Bekoff \& Byers, 1998; Burghardt, 2005), breeds of dogs that display distinctly different predatory motor patterns may provide insight into a biological mechanism (i.e., predatory motor patterns) influencing the different motivations hypothesized in solitary and social play. Although many companion and showconformation dogs are selectively bred for morphological traits, some working breeds still undergo intense behavioral selection for the expression of these predatory motor patterns (Udell, Ewald, Dorey, \& Wynne, 2014). Furthermore, some breeds are selected for increased, decreased, or unchanged levels of these motor patterns, relative to the wolf, where the fully intact canine predatory motor sequence (orient $>$ eye $>$ stalk $>$ chase $>$ grab-bite $>$ kill-bite $>$ dissect $>$ consume) is reliably triggered by the movement of prey (Coppinger \& Coppinger, 2001; Coppinger \& Schneider, 1995). Herding dogs, for example, show exaggeration of the eye, stalk, and chase motor patterns, whereas retrievers show an exaggeration of chase and grab-bite; LGDs inhibit all components of the predatory sequence (Coppinger \& Coppinger, 2001; Udell et al., 2014). Given that breed-specific motor patterns were recently found to be predictive of dogs' responsiveness to human gestures (Udell et al., 2014), it is plausible that the motivation to engage in social play may be regulated not only by environmental factors but also by biological factors in the form of these directly observable breed-specific motor patterns.

Since solitary play with objects resembles predatory behavior in both form and motivation (Bradshaw et al., 2015), it follows that breed types with distinct predatory motor patterns should exhibit different levels of solitary play when presented with objects. Furthermore, breed differences in the motivation to engage in different forms of play (due to different artificial selection pressures; Rooney, Bradshaw, \& Robinson, 2000) has been recently suggested as a topic worthy of study and relevant to our understanding of both the evolutionary and lifetime factors that govern play behavior (Bradshaw et al., 2015); specifically, breed-specific predatory motor patterns may represent an underlying biological mechanism central to our theoretical understanding of play in domestic dogs. Although breed differences in object play has been shown previously (Burghardt et al., 2016), no study to date has demonstrated an effect of breed on play behavior in domestic dogs with a direct comparison to social and solitary play (Bauer \& Smuts, 2007; Bradshaw et al., 2015). In addition, it is currently unknown whether breeds that possess different predatory motor sequences differ in their propensities to engage in different forms of play (i.e., social and solitary play) at different rates, or in the impact 
of environmental manipulations on rates and forms of play behavior, and whether there are interactions between breed and the impact of environmental manipulations.

The aim of the present study was to examine experimentally the impact of breed and environmental manipulations, and their interaction, on play in domestic dogs. Breedmatched dyads with working experience and of equivalent age, sex, and neuter status ratios were placed in four experimental test conditions and two control conditions in randomized orders. In the experimental conditions, the dogs were exposed to owner attention, attention from a less familiar person, a toy, and escape from aversive, and in the control conditions to an inattentive owner and being left alone. We hypothesized that breed differences would be observed in dogs' predispositions to engage in solitary compared to social play as well as in the experimental conditions that would motivate certain breeds to play. Specifically, we predicted that

Breeds with intact predatory motor sequences (herders and retrievers) would exhibit higher social and solitary play levels than breeds with inhibited predatory motor sequences (LGDs).

Across all breeds, higher levels of play would be observed in conditions in which external stimulation occurred (human attention, a moving toy, or termination of an aversive event) relative to conditions in which no external stimulation was present across all breeds.

Breeds with intact predatory motor sequences (herders and retrievers) would exhibit higher play levels in response to stimuli that trigger movement (toys) than breeds with inhibited motor sequences (LGDs).

Breeds selected for direct responsiveness to familiar humans in working roles (herders and retrievers) would play at higher levels in response to an owner in comparison to LGDs.

\section{Method}

\section{Subjects}

A total of 30 pairs of adult dogs from three different breed types were included in the study (see Table 1). Specific breeds were categorized by breed type based on their historical working roles (American Kennel Club, 2007). Within each pair, both subjects shared the same owner, were of the same breed type, from working lines, and had experience in their working roles. Breed types were selected by a combination of both distinctiveness in predatory motor patterns (e.g., Coppinger \& Coppinger, 2001; Udell et al., 2014), and that were similar in size and morphology. Dog breed type was determined via morphological markers (Coppinger \& Coppinger, 2001; Udell et al., 2014) as well as via owner report. To prevent negatively affecting dog safety and welfare, individual dogs that reportedly engaged in severe separation-related behaviors (e.g., destruction, excessive vocalization, attempts to escape, immediate urination/defecation) in response to their owners leaving them unattended were excluded from the study. Subjects were recruited from regional breed clubs and working/sporting dog organizations as well as via Craigslist advertisements and flyers at local dog parks. Subjects were volunteered by their owners by contacting the lead author via e-mail or phone and enrolled in the study following the owners' affirmation that their dogs met eligibility criteria for the study as provided by the experimenters.

\section{Behavioral monitoring}

Social and solitary play were operationally defined prior to the start of the study (see Table 2). Play initiation behaviors (whether for social or solitary play) were recorded if they occurred for at least 1 continuous second, whereas social and solitary play bouts were recorded if they occurred for at least 3 continuous seconds. The duration of each type of play was coded from high-definition video footage independently by two coders who were blind to the purposes of the study. Coders reviewed video footage and used either stopwatches or noted time from the playback of video software programs to track the number of seconds elapsed between the onset and offset of play as well as stimulus (e.g., toy) engagement. Interobserver agreement was calculated by taking the durations of solitary and social play separately coded by both observers from a random subset of $33 \%$ of all sessions, dividing the shorter duration by the longer duration and multiplying by $100 \%$. Interobserver reliability for social play and solitary play across conditions was $89.0 \%$ and $90.0 \%$, respectively.

\section{Procedures}

All subjects were tested in their homes where the owner reported that the dogs regularly engaged in play. All dyads were tested in the morning (8:00 a.m. to 11:00 a.m.) or evening (5:00 p.m. to 7:00 p.m.), when play levels would be expected to be highest (according to owner reports), and to control for effects of time of day. If the owner reported either dog within a dyad to be more playful at one time of day over the other, the dyad was scheduled for the time period in which they were reported to be most playful. If no difference was reported, the time of testing depended on owner and experimenter availability. For each breed group, eight dyads were tested in the morning, and two were tested in the evening; thus, the distribution of dyads run in the morning and in the evening were even across breeds. Given that object play has been previously linked to food deprivation (Hall \& Bradshaw, 1998), all sessions were run $30 \mathrm{~min}$ to $2 \mathrm{hr}$ following the subjects' last feeding. Each pair of subjects underwent the six 5-min experimental conditions in a 
Table 1 Life history characteristics of dog and dog dyad subjects

\begin{tabular}{|c|c|c|c|}
\hline Breed type & Name & Breed & Age (months) \\
\hline \multirow[t]{10}{*}{ Livestock Guarding Dogs (LGDs) } & Trinity $q$ \& Roxie $q$ & Anatolian Shepherd & 10,48 \\
\hline & Benny \& Kori우 & Anatolian Shepherd & 6,24 \\
\hline & Cody \& Cooper & Great Pyrenees & 48,60 \\
\hline & Denny \& Old Man & Great Pyrenees & 84,132 \\
\hline & Kipper \& Zooeyㅇ & Great Pyrenees & 60,12 \\
\hline & Addicus \& Lindsey우 & Great Pyrenees & 48,72 \\
\hline & Ava + \& Simba & Great Pyrenees, Great Pyrenees $\times$ Anatolian & 7,7 \\
\hline & Nagine 9 \& King & Anatolian Shepherd & 108,12 \\
\hline & Shasta + \& Sherman & Great Pyrenees & 60,24 \\
\hline & Trip \& Bernie & Great Pyrenees & 48,48 \\
\hline \multirow[t]{10}{*}{ Herders } & Bek \& Bizcuit & Border Collie & 84,12 \\
\hline & $\operatorname{Rev} \uparrow \&$ Blitz & Border Collie & 72,48 \\
\hline & Nikki우 \& Nora우 & German Shepherd Dog & 24. 24 \\
\hline & & Belgian Malinois, German Shepherd Dog & 24,60 \\
\hline & Tique \& Jolene + & Australian Shepherd & 48,84 \\
\hline & Bella ${ }_{+} \&$ Maybe + & Australian Shepherd & 12,48 \\
\hline & Vega + \& Amelia ${ }_{+}$ & German Shepherd Dog & 48,120 \\
\hline & Abbey 9 \& Ranger & German Shepherd Dog & 12,12 \\
\hline & Rebel \& Blade & German Shepherd Dog & 12,12 \\
\hline & Dakota \& Ruthie + & German Shepherd Dog & 12,48 \\
\hline \multirow[t]{10}{*}{ Retrievers } & Copper \& Gator & Golden Retriever & 96,48 \\
\hline & Topper \& Moxie우 & Labrador Retriever & 24,96 \\
\hline & Mena + \& Eyla + & Labrador Retriever & 24,96 \\
\hline & Mika + \& $\mathrm{Ada}+$ & Labrador Retriever & 120,144 \\
\hline & Rogue + \& Tolkein & Labrador Retriever & 84,28 \\
\hline & Shayla $q$ \& Cassidy우 & Labrador Retriever & 12,12 \\
\hline & Tiko우 \& Jackson & Golden Retriever & 28,36 \\
\hline & Dawn우 \& Tess 우 & Labrador Retriever & 36.120 \\
\hline & Georgia \& Davy & Labrador Retriever & 96,7 \\
\hline & Lulu우 \& Sally우 & Labrador Retriever & 84,48 \\
\hline
\end{tabular}

Individuals that are spayed/neutered are italicized. Females are denoted by symbols

randomized order (described in detail below). Four of the six conditions (owner attention, less familiar person, toy, and escape from aversive) were included in order to simulate either social play or solitary play in pairs of dogs;

Table 2 Operational definitions of dog behaviors measured

\begin{tabular}{lc}
\hline Behavior & Definition \\
\hline Solitary play & $\begin{array}{c}\text { Non-reciprocal motor patterns (e.g., pawing, play bow) directed toward an inanimate object without } \\
\text { engaging or orienting toward another conspecific. May also include locomotor behaviors (e.g., inhibited } \\
\text { running, voluntary downs) not necessarily directed toward inanimate objects, conspecifics, or people. } \\
\text { Simultaneous, reciprocal affiliation between conspecifics that are not agonistic and included at least one of } \\
\text { the following components: self-handicapping, inhibited biting, wrestling, chasing, and exaggerated predatory } \\
\text { beahviors. Play initiation behaviours (e.g., play bow, pawing) from one dog were only recorded if they led to } \\
\text { a reciprocal play bout within three seconds. }\end{array}$ \\
\hline
\end{tabular}


two of the conditions (owner control and alone control) served as controls to assess background play rates not related to the experimental manipulations.

\begin{abstract}
Alone control In the alone control condition, a camera was set up in the test area to record the behavior of both subjects. The condition began immediately once both the owner and experimenter were out of sight and inaudible to subjects. This condition was predicted to facilitate minimal levels of play. To avoid unintentionally inhibiting play in the alone condition by placing dogs into unfamiliar situations, subjects were kept in the test area in ways that owners reported was typical for that dyad. In addition, the test area was always enclosed throughout all experimental conditions (in ways owners reported was familiar to each dyad) to minimize any sensitization to these environmental changes.
\end{abstract}

Owner attention In the owner attention condition, the owner initially provided continuous verbal praise and petting to one dog exclusively. Attention from the owner was only provided to both subjects if social play occurred. The owner was instructed not to directly encourage play or deliver play signals (e.g., clapping, bowing, lunging, patting floor; Rooney, Bradshaw, \& Robinson, 2001) to either dog. This condition has been previously shown to promote social play levels in captive handreared wolves and wolf-dog crosses (e.g., Mehrkam, Verdi, \& Wynne, 2014) and pet dogs (Mehrkam \& Wynne, unpublished data); thus, it was predicted that this condition would increase social play levels in the dogs in the present study as well.

Less familiar person The less familiar person condition was procedurally identical to the owner attention condition; the only difference was that the experimenter delivered the attention and praise. This condition was expected to increase play due to arousal from a relatively novel person.

Owner control In the owner control condition, the owner entered the testing area and ignored both subjects throughout the session. To increase the salience of the unavailability of owner attention, the owner performed a task and held an associated stimulus that the dogs reportedly had a history with while being ignored (e.g., reading a book, gardening, cleaning; Udell, Dorey, \& Wynne, 2011). The purpose of the owner control condition was to control for the presence of the owner alone as a motivator for play; thus, it was predicted that this condition would produce minimal levels of play as well.

Toy The toy condition was preceded by a brief choice test in which the experimenter laid out three previously unused toys of varied shape and sensory consequence (i.e., a vinyl squeak toy, a rope tug, and a tennis ball for auditory, tactile, and movement consequences, respectively) approximately $1 \mathrm{~m}$ in front of both dogs. The same three toys were presented to all subjects. The first toy that either one or both dogs engaged with for at least $10 \mathrm{~s}$ was chosen as the toy to be used in this condition. At the start of the toy condition, the experimenter engaged in the appropriate manipulation for the chosen toy to entice the subjects (squeaked and dropped the vinyl squeak toy, shook the tug, or threw the tennis ball). The experimenter only manipulated the toy (without providing attention to the subjects) if $15 \mathrm{~s}$ elapsed in which at least one subject was not engaging with the toy; otherwise, the experimenter ignored the subjects. This condition was included because toys are cited as promoting both human-dog and dog-dog social play (e.g., Rooney et al., 2000); thus, it was expected that both forms of play would increase in this condition.

Escape from aversive The escape from aversive condition began at the moment the dog was reintroduced to the testing area immediately following a mildly unpleasant event (10-min separation from the other dog and the owner). Experimenter and owner were both present outside of the testing area but ignored the subjects throughout the session. This condition was presented based on prior literature in mammals that social deprivation increases the motivation to play with conspecifics (e.g., Beatty, Dodge, Dodge, White, \& Panksepp, 1982; Humphreys \& Einon, 1981); thus, it was expected that this condition would increase social play levels in dogs.

\section{Statistical analysis}

A linear mixed-effects model (Bates, Maechler, Bolker, \& Walker, 2013) was fit for the dependent variables social play and solitary play. For social play, pairs were treated as the individual unit, because, by definition, both individuals had to have equivalent durations of social play. For solitary play, subjects were treated individually, as they could engage in independent play for different lengths of time. Fixed-effect predictors of the models were the difference in age between the two dogs in each dyad (previously shown to influence play in dog-dog dyads; Bauer \& Smuts, 2007), the sex of the group (male-male, malefemale, female-female), the neuter status of the group of dyads (intact-intact, fixed-intact, fixed-fixed), the experimental condition (escape from aversive, less familiar person, owner attention, toy), the breed group (herder, retriever, or LGD), and an experimental condition by breed group interaction. An interaction between neuter status and sex was not included because our sample did not include any female-female intact-fixed pairs, thereby making it impossible to estimate this parameter. For social play, a random intercept term was included for each dog pair. For solitary play, a random intercept term was included for each individual dog. The model was then subjected to backwards elimination based on the Akaike information criterion (AIC) using the step function in $\mathrm{R}$ lmerTest packages in $\mathrm{R}$ statistical software (Kuznetsova, Brockhoff, \& Christiansen, 2013). Post hoc tests for significant predictors were computed 
using the lsmeans package with a Tukey adjustment for multiple comparisons. An alpha level of 0.05 was adopted.

\section{Results}

First, we evaluated whether social and solitary play were elevated in the experimental conditions compared to the control conditions (see Figs. 1 and 2). Social play was higher in the experimental conditions that did not include a person (i.e., the toy and escape from aversive conditions) than in the alone control condition, $t(147)=2.83, p=.027$. Social play was also higher in the social experimental conditions (owner attention and less familiar person) than the alone control condition, $t(147)=2.99, p=.02$, but was not higher than in the owner control condition, $t(147)=2.19, p=.13$. Solitary play was highest in the nonsocial toy and escape from aversive conditions than in the alone control condition, $t(297)=4.55, p<$ .001 , or the owner control condition, $\mathrm{t}(297)=4.11, p<.001$. However, there was no difference in solitary play between the experimental conditions that included a person compared to the owner control condition, $t(297)=1.62, p=.37$, or alone control condition, $t(297)=2.06, p=.17$. Thus, the experimental conditions engendered more play than the relevant control conditions. We therefore focused subsequent analysis on the experimental conditions.

\section{Social play}

Figure 1 shows social play levels across each experimental test and control condition for all dyads and breeds group. Following backwards elimination of the model described under statistical analyses, neuter status was the only significant predictor of social play, $F(2,27)=5.86, p<.01$; see Fig. 3). Post hoc tests indicated that pairs where one was fixed and the other was intact showed the greatest rates of play compared to groups in which both were fixed, $t(27)=2.57, p=.04$, or both were intact, $t(27)=3.25, p=.008$; see Fig. 3). The following factors were removed as nonsignificant during model selection: the dog's age, $F(1,22)=1.77, p=.19$; sex, $F(2,23)=$ $2.12, p=.15$; breed, $F(2,25)=0.06, p=.95$; experimental condition, $F(3,87)=2.45, p=.07$; and a breed by experimental condition interaction, $F(6,81)=1.99, p=.08$. The effect of condition was close to the assigned alpha level $(p=.069)$.

\section{Solitary play}

Figure 2 shows solitary play levels across each experimental test condition for all dyads and breed groups. The following effects were removed from the regression model as nonsignificant: the dog's age, $F(1,54)=0.41, p=.52$; sex, $F(1,56)=$ $3.42, p=.07$; neuter status, $F(1,55)=1.89, p=.18$; and the experimental condition by breed interaction, $F(6,171)=.75, p$
$=.61$. Overall, solitary play levels were significantly predicted by both experimental condition, $F(3,177)=24.17, p<$ .001 , and breed, $F(2,57)=3.95, p=.025$. With respect to experimental condition, the toy condition produced the highest levels of play compared to the escape from aversive, $t(177)=-7.91, p<.001$, mean difference and $S E: 56 \pm 7 \mathrm{~s}$; less familiar person, $t(177)=-5.64, p<.001$, mean difference and $S E: 40 \pm 7 \mathrm{~s}$; and owner attention conditions, $t(177)=-6.54, p$ $<.001$, mean difference and $S E: 47 \pm 7$ s. With respect to breed, the retrievers showed a trend for overall higher solitary play than herders, $t(57)=-2.23, p=.08$, mean difference and $S E: 19 \pm 9$ s, and showed significantly higher play than LGDs, $t(57)=-2.60, p=.03$, mean difference and SE: $23 \pm 9 \mathrm{~s}$. Herders and LGDs did not differ significantly in their overall levels of solitary play, $t(57)=0.37, p=.93$.

In addition, considering just the type of play across all breeds and experimental test conditions, solitary play occurred more often than social play, $t(208.32)=2.826, p=.005$. A summary of all findings for social and solitary play with respect to breed type, sex, neuter status, and environmental context can be found in Table 3 .

\section{Discussion}

The aims of this study were to identify proximate causes of play behavior in domestic dogs (specifically, the influences of environmental stimuli). Furthermore, we tested whether breed types of domestic dogs differed in their motivation to engage in social and solitary play and whether breed $\times$ environmental interactions influenced either form of play. Lastly, we tested whether social and solitary play were differentially facilitated by social and nonsocial stimuli. We hypothesized that breed differences would be observed in dogs' predispositions to engage in solitary compared to social play as well as in the experimental conditions that would motivate certain breeds to play. Specifically, we expected that breeds selected for direct responsiveness to familiar humans in working roles (herders and retrievers) would play at higher levels in response to an owner in comparison to LGDs. In contrast, we expected that breeds with intact predatory motor sequences (herders and retrievers) would exhibit higher play levels in response to stimuli that trigger movement (toys) than breeds with inhibited motor sequences (LGDs).

\section{Effects of breed on solitary and social play levels}

With respect to breed, it was hypothesized that breeds with intact predatory motor sequences (herders and retrievers) would exhibit higher social and solitary play levels than breeds that exhibit inhibited predatory motor sequences (LGDs). Of the three breed types tested, retrievers were significantly more likely to engage in solitary play overall than 

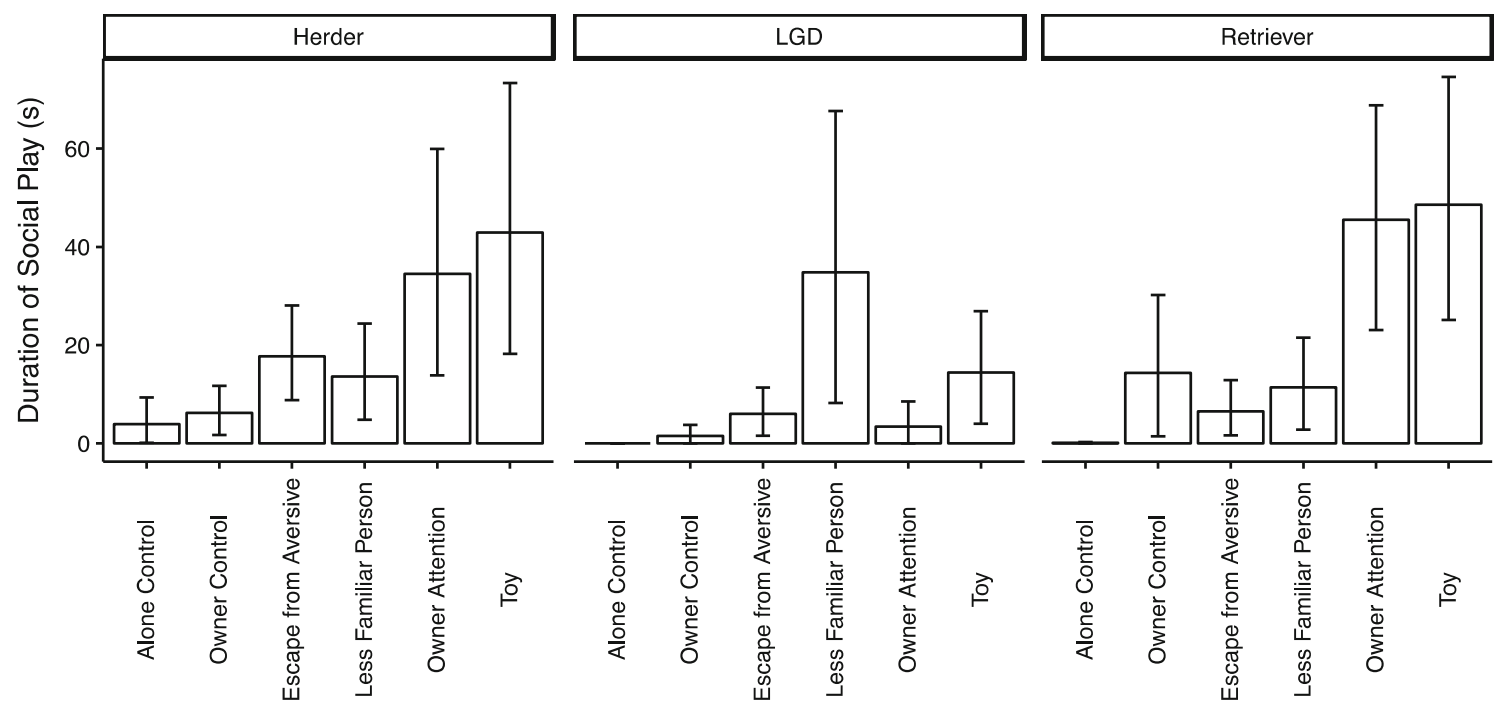

Fig. 1 Mean social play durations (in seconds) across experimental conditions for dyads of all breed -types. Vertical bars represent $95 \%$ confidence intervals

LGDs, and we found a trend for more play in retrievers compared to herders; however, social play levels did not differ significantly across breed types. Furthermore, retrievers showed overall the highest levels of play regardless of experimental condition; thus, no significant breed-condition interactions on either social play or solitary play were observed.

\section{Effects of environmental context on solitary and social play levels}

With respect to environmental condition, we hypothesized that across all breeds, higher levels of play would be observed in conditions in which external stimulation occurred (human attention, a moving toy, or termination of an aversive event) relative to conditions in which no external stimulation was present across all breeds. All dogs - regardless of breed-were more likely to engage in solitary play when a toy was present compared to when an aversive event was terminated. In contrast to social play, however, differences in solitary play were strongly influenced by multiple experimental conditions, independent of breed. Furthermore, the structure of play was influenced by context and not by breed; specifically, social play emerged at similar levels in both social and nonsocial contexts, whereas solitary play emerged at higher levels in nonsocial contexts. Perhaps not surprisingly, solitary play occurred most often in the nonsocial conditions. In all breeds, solitary play was largely controlled by the presence of a toy; however, retrievers generally exhibited more solitary play with the toy than did LGDs.
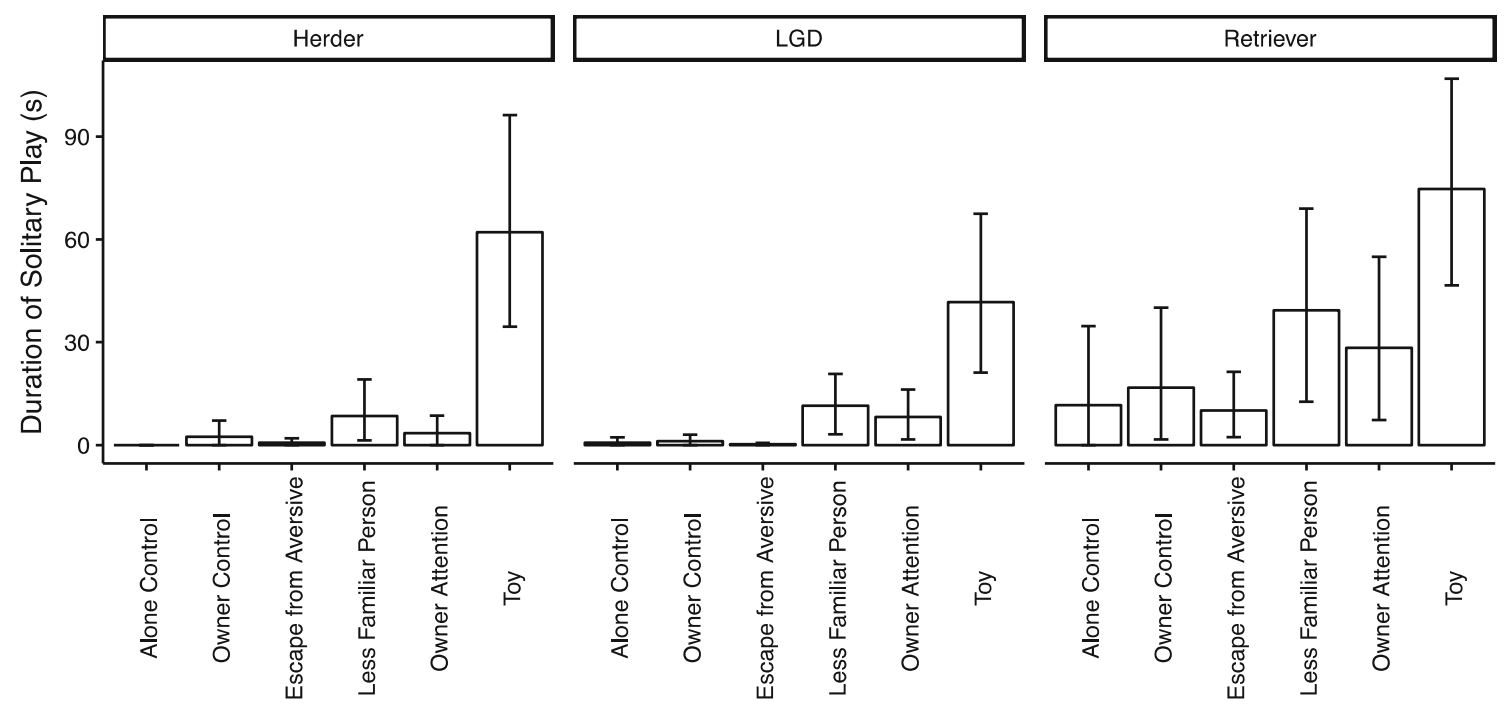

Fig. 2 Mean solitary play durations (in seconds) across experimental conditions for dyads of all breed- types. Vertical bars represent $95 \%$ confidence intervals 


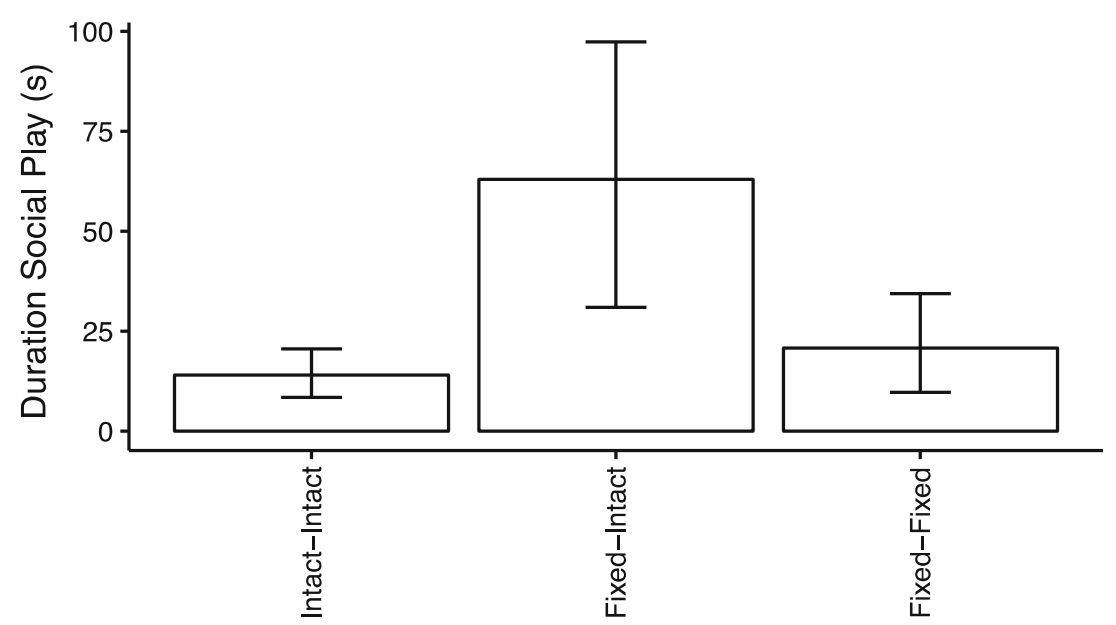

Fig. 3 Mean duration of social play (in seconds) across the experimental conditions by dyad sex status. Vertical bars represent $95 \%$ confidence intervals

This finding is consistent with our hypothesis that breed types with inhibited predatory motor sequences may engage in lower levels of solitary play than breed types with intact predatory motor sequences in contexts that stimulate those motor patterns. Solitary object play has been linked to predatory drive in domestic cats (Hall \& Bradshaw, 1998), and our findings extend this relationship to domestic dogs as well. However, it should be noted that Burghardt et al. (2016) did not find hunger to be the primary motivation of object play in Welsh Terriers, Vizslas, and Standard Poodles and further suggested that this relationship may be age dependent. Since the present study tested only adult dogs, we are unable to claim this from our results. Further research on the topic of play in dogs - as well as other species - should aim to conduct studies on object play that follow individual subjects across developmental stages of their life.

When considering the motivations underlying solitary play in domestic dogs, it is worth noting that all subjects in the present study were adult dogs from working lines and had relevant working experience in their lives; if predatory behavior does underlie the motivation to engage in solitary play in domestic dogs as is the case for select other species (e.g., Hall $\&$ Bradshaw, 1998; Pellis, 1991), it may be that working populations of dogs is more motivated to engage in types of play that afford that opportunity. Indeed, Burghardt et al. (2016) did not find support for a relationship between hunger and motivation to engage in object play in domestic dogs across three distinct breeds (based on developmental milestones) bred for a combination of show, performance, and companionship. Another potential proximate explanation for this finding may be that relevant motivating operations were not manipulated in either study (e.g., dogs not food deprived for extended periods of time, as was the case with cats in Hall \& Bradshaw, 1998). It is also possible that such a motivation may not be evolutionarily relevant to domesticated animals living in pet homes or for individuals likely selected for increased play repertoires.
Although it has been claimed that the majority of dogs prefer social play with humans over solitary play (Pullen, 2011), in the present study, social play between dogs occurred less often than did solitary play. Solitary play may be less energetically expensive, afford opportunities to interact with relatively novel or restricted resources not continuously available, or may be less likely to incur competition risks or injuries to its participants relative to social play with another conspecific. Thus, questions examining the influence of both proximate and ultimate causes of solitary and social play directly are worthy of future study. Given that not all experimental conditions provided opportunities for play with humans, conclusive statements about breed differences in preference for social play with humans versus solitary play cannot be stated, though this should be assessed in future studies as well.

\section{Effect of neuter status, sex, and age on social and solitary play}

In addition to the effects of experimental condition and breed, the effect of neuter status on social play levels is especially novel. Specifically, dyads that included both fixed and intact individuals engaged in social play at significantly higher rates than did dyads that had the same neuter status (i.e., fixedfixed or intact-intact). Although no prior research has reported this finding in dogs, experimental research with rats has found that males that were castrated at birth reduced their play fighting and that young females whose levels of testosterone were experimentally increased were involved in more play fights (Beatty et al., 1982; Olioff \& Stewart, 1978). Pellis, Pellis, and Kolb (1992) also found that male rats that were given testosterone injections initiated play fighting at significantly higher rates than did controls. Although these prior findings suggest that dyads that consist of individuals that are both intact should engage in higher levels of play, it may be that social play in intact-intact dyads more often leads to aggression than in intact-fixed dyads, given that testosterone has also long 
Table 3 Summary of findings for social and solitary play levels across genetic and environment factors

\begin{tabular}{|c|c|c|}
\hline & Social play & Solitary play \\
\hline Breed & $\begin{array}{l}\text { No significant breed differences observed } \\
\text { between retrievers, herders, or LGDs }\end{array}$ & $\begin{array}{l}\text { Retrievers significantly more likely to engage } \\
\text { in solitary play overall than LGDs } \\
\text { Observed trend (non significant) for more play } \\
\text { in retrievers compared to herders }\end{array}$ \\
\hline Sex & None observed & None observed \\
\hline Neuter status & $\begin{array}{l}\text { Significant effect of neuter } \\
\text { status on social play levels observed } \\
\text { Dyads containing both a fixed and an intact dog } \\
\text { exhibited significantly higher social play rates than } \\
\text { dyads containing dogs with the same neuter status }\end{array}$ & None observed \\
\hline Environmental Effects & $\begin{array}{l}\text { Higher levels observed in the Toy and Escape From } \\
\text { Aversive conditions than in nonsocial } \\
\text { control conditions } \\
\text { Higher levels observed in the social experimental } \\
\text { conditions (owner attention and Less Familiar } \\
\text { Person) than in nonsocial control } \\
\text { (but not social control) } \\
\text { Occurred at similar levels in social } \\
\text { and nonsocial contexts }\end{array}$ & $\begin{array}{l}\text { Highly significant effect observed across all } \\
\text { breeds compared } \\
\text { Solitary play observed at higher levels in } \\
\text { nonsocial contexts compared to social contexts; } \\
\text { nonsocial contexts higher than } \\
\text { both control condition } \\
\text { Toy produced highest solitary play } \\
\text { levels across all breeds } \\
\text { Retrievers exhibited more solitary play } \\
\text { with a toy than LGDs }\end{array}$ \\
\hline Breed $\times$ Environment Interactions & $\begin{array}{l}\text { No significant breed-condition interactions on } \\
\text { social play were observed }\end{array}$ & $\begin{array}{l}\text { No significant breed-condition interactions } \\
\text { on solitary play observed }\end{array}$ \\
\hline Overall Differences & $\begin{array}{l}\text { Social play occurred less overall than } \\
\text { did solitary play }\end{array}$ & $\begin{array}{l}\text { Social play occurred more overall than } \\
\text { did social play }\end{array}$ \\
\hline
\end{tabular}

been linked to male aggression (Nelson, 2005). Furthermore, the fact that neuter status influenced social play levels but not solitary play levels may also suggest that role reversalwhereby a dominant animal temporarily uses less advantageous strategies to allow a subordinate animal to maintain a dominant role during play-could be an important factor. While male-female dyads are less likely to engage in these role reversals than same-sex dyads (Dugatkin, 2013), this effect of neuter status is surprising given that the majority of intact-fixed dyads in our study were male-female dyads. It may be possible that change in neuter status (and hence hormone levels) can alter the structure and function of dyadic play in domestic dogs. However, future research that experimentally controls for neuter status in dog-dog dyads would be needed to test these hypotheses with respect the relationship between neuter status and social play.

It is also worth noting that other factors such as age and sex did not significantly influence social or solitary play levels in this study. Although this provides strong support that play behavior here was more strongly influenced by genetic (breed) and specific stimuli in the direct environment, it remains possible that interactions may be observed with a larger sample that can control for these fixed variables experimentally. Given that play is typically characteristic of juveniles in many species, the lack of age effect may theoretically be due to an increased degree of neotony throughout the life span in domestic dogs relative to other species as well as our selection criteria. However, these findings may also be due to the uneven sex ratios among the dyads in our sample; we had only one female-female dyad among the LGDs and only one male-male dyad among the retrievers. Future research on play in domestic dogs should continue to examine the influences of variables such as sex, neuter status, and age; such information would not only be theoretically important to the understanding of play in domestic animals but also potentially to dogs' suitability as companion animals.

\section{Motivational bases for social and solitary play in dogs}

In light of these findings, although predatory motor patterns may be observed during social play, social play may not necessarily have a motivational basis linked to predatory behavior; rather, social play may serve to regulate stress or competition between dogs. Evidence that social play appears to regulate stress before events highly predictive of conflict has been found in chimpanzees (Palagi, 2007), and Brueggeman (1978) suggested that social play promotes the establishment, maintenance, and testing of conspecific relationships in rhesus macaques. As such, social play may serve to reinforce social bonds between familiar dogs in the presence of an object that evokes intraspecific competition (such as a toy or attention from a person), or even maintain social bonds or dominance relationships after a stressful event or separation. Given that social play was most frequently observed when a single toy or 
attention to only a single animal was initially available, social play in domestic dogs may reflect motivations that produce competition between conspecifics as when two dogs compete for attention from a single, familiar owner or for a novel or high-value toy, whereas solitary play may reflect motivations linked to predatory motor patterns.

This conclusion about social play would also explain why social play occurred at relatively low levels in the escape from aversive condition compared to other test conditions; though it might be predicted that high arousal and a relatively low-stress context would facilitate play, the data obtained from the present study do not support this hypothesis. Thus, it may be that the escape from aversive context does not facilitate or promote predatory motor patterns, nor does it involve a context of potential conflict. Another possible explanation is that social play is more energetically expensive and riskier to engage in than solitary play (Smith et al., 1999) and may thus be expected to occur at lower frequencies overall. Future experimental studies on the motivational basis for social and solitary play in social mammals are needed to test these potential hypotheses.

\section{Current limitations and future directions}

Given the apparent sensitivity of play behavior to environmental cues, it is of great importance to consider individual history and experiences of the subjects when designing experimental conditions. For example, in attempt to mitigate unintentionally exaggerated low levels of play in the alone condition due to simply being confined, the way the dogs were kept in the test area necessarily varied across individual dyads based on what owners reported was typical for that dyad. For example, some dyads were routinely used to being left unattended in their backyard or in a large outdoor pen, whereas other dyads were used to being left in a room with baby gates, closed doors while their owner and the experimenter left the room. In addition, the test area was always enclosed throughout all experimental conditions, not just the alone condition, to reduce sensitization to these environmental changes. Although the researchers did not include dogs in the study that reportedly showed separation-related behaviors, nonetheless, it is still possible that dogs may have exhibited low levels of play as a result of discomfort or uncertainty, especially with the recent arrival of an unfamiliar experimenter to their home; thus, future research or conditions that require the absence of the owner or experimenter should take similar considerations into account and further document any separation-related behaviors observed during the experimental conditions, rather than simply relying on owner report.

Given that pet dogs of certain breeds were used as subjects, a potential limitation of the present study that should be considered may be with respect to the selection of subjects- particularly, owners' self-selection of the dogs they volunteered. For example, owners may have only volunteered their dogs if their dogs seemed playful in certain contexts or were tolerant of novel experiences or of the presence of both familiar and unfamiliar people, knowing that the dogs would be tested in their home by the researchers. This is particularly relevant to the play levels we observed in the less familiar person and escape from aversive conditions in our study. Although it is not possible to determine this within the present dataset, future studies that use dogs housed and kept strictly for working purposes may help ensure a sample that is more representative of the breed's population as a whole and reduce the possibility of an overrepresentation of certain temperaments or personality characteristics. This is especially important for research examining livestock guarding dogs, specifically, as these breeds are expected to show some reserve or increased arousal and territoriality in the presence of unfamiliar people.

Although play has traditionally been characterized as more elusive than other forms of behavior, the findings of this study suggest that play behavior in domestic dogs, like many other well-studied behaviors, is a product of genetic, breed-typical predispositions, contextual factors, and experience with specific stimuli acquired during the lifetime of the individual. Furthermore, these results demonstrate how different stimuli evoke solitary and social play, which both appear to be influenced by different proximate causes. This study provides evidence that solitary play can be stimulated immediately in experimental contexts by presenting environmental stimuli that evoke play topography. This is the first study to demonstrate a relationship between breed type and the form of play behavior in domestic dogs. By providing animal behaviorists with a means to study play in controlled settings, and making it more amenable to experimental analysis, these findings should stimulate further studies examining the proximate causes of play in domestic dogs and other species.

Acknowledgments We thank the dogs and dog owners who volunteered their time to make this study possible. We also thank Tori Self, Cassandra Vazquez, and Ryan Talbot for assistance with data collection and behavioral coding. We also thank Jane Brockmann, Timothy Vollmer, Jesse Dallery, and two anonymous reviewers for their helpful comments on this manuscript.

\section{References}

Ahloy Dallaire, J., \& Mason, G. J. (2016). Play in juvenile mink: Litter effects, stability over time, and motivational heterogeneity. Developmental Psychobiology, 58, 945-957.

American Kennel Club. (2007). The complete dog book (20th ed.). New York: Random House.

Bates, D., Maechler, M., Bolker, B., \& Walker, S. (2013). Lme4: Linear mixed-effects models using Eigen and S4 (R package Version 1.05). Retrieved from http://CRAN.R-project.org/package $=1 \mathrm{me} 4$

Bauer, E. B., \& Smuts, B. B. (2007). Cooperation and competition during dyadic play in domestic dogs, Canis familiaris. Animal Behavior, 73, 489-499. 
Beatty, W. W., Dodge, A. M., Dodge, L. J., White, K., \& Panksepp, J. (1982). Psychomotor stimulants, social deprivation and play in juvenile rats. Pharmacology Biochemistry and Behavior, 16, 417-422.

Bekoff, M. (1995). Play signals as punctuation: The structure of social play in canids. Behavior, 132, 419-429.

Bekoff, M. (2001). Social play behavior: Cooperation, fairness, trust, and the evolution of morality. Journal of Conscious Studies, 8, 81-90.

Bekoff, M., \& Byers, J. (1998). Animal play: Evolutionary, comparative, and ecological perspectives. Cambridge: Cambridge University Press.

Bradshaw, J. W. S., Pullen, A. J., \& Rooney, N. J. (2015). Why do adult dogs "play"? Behavioral Processes, 110, 82-87.

Brueggeman, J. A. (1978). The function of adult play in free-living Macaca mulatta. In E. O. Smith (Ed.), Social play in primates (pp. 169-192). New York: Academic Press.

Burghardt, G. (2005). The genesis of animal play. Cambridge: Cambridge University Press.

Burghardt, G.M., Albright, J.D., \& Davis, K.M. (2016). Motivation, development and object play: comparative perspectives with lessons from dogs. Behaviour 153, 767-793.

Coppinger, R., \& Coppinger, L. (2001). Dogs: A new understanding of canine origin, behavior and evolution. Chicago: University of Chicago Press.

Coppinger, R., \& Schneider, R. (1995). The evolution of working dogs. In J. S. Serpell (Ed.), The domestic dog: Its evolution, behavior and interactions with people (pp. 21-47). Cambridge: Cambridge University Press.

Cordoni, G. (2009). Social play in captive wolves (Canis lupus): Not only an immature affair. Behavior, 146, 1363-1385.

de Haan, J. A. (1952). The play of a young solitary chimpanzee. Behavior, $4,144-156$.

Dugatkin, L. A. (2013). Principles of animal behavior: Third international (studentth ed.). New York: W. W. Norton.

Fagen, R. (1981). Animal play behavior. New York: Oxford University Press.

Hall, S. (1998). Object play by adult animals. In M. Bekoff \& J. Byers (Eds.), Animal play: Evolutionary, comparative, and ecological perspectives (pp. 45-60). Cambridge: Cambridge University Press.

Hall, S., \& Bradshaw, J. W. S. (1998). The influence of hunger on object play by adult domestic cats. Applied Animal Behavior Science, 58, 143-150.

Harcourt, R. (1991). Survivorship costs of play in the South American fur seal. Animal Behavior, 42, 509-511.

Hinde, R. A. (1974). Biological basis of human social behavior. New York: McGraw-Hill.

Horowitz, A. C. (2009). Domestic dogs (Canis familiaris) use visual attention cues when play signaling. Journal of Veterinary Behavior: Clinical Applications and Research, 4, 53-54.

Humphreys, A. P., \& Einon, D. F. (1981). Play as a reinforcer for mazelearning in juvenile rats. Animal Behavior, 29, 259-270.

Kuznetsova, A., Brockhoff, B., \& Christensen, H.B. (2013). LmerTest: Tests for random and fixed effects for linear mixed effect models (lmer objects of lme4 package) (R package version 2.0-3). Retrieved from http://CRAN.R-project.org/package=lmerTest

Martin, P., \& Caro, T. M. (1985). On the functions of play and its role in behavioral development. In J. S. Rosenblatt, C. Beer, M.-C. Busnel, \& P. J. B. Slater (Eds.), Advances in the study of behavior (Vol. 15, pp. 59-103). New York: Academic Press. Retrieved from http:// www.sciencedirect.com/science/article/pii/S0065345408604878

Mehrkam, L. R., Verdi, N. L., \& Wynne, C. D. L. (2014). Human interaction as environmental enrichment for pair-housed wolves and wolf-dog hybrids. Journal of Applied Animal Welfare Science, 17, 43-58.

Mehrkam, L. R., \& Wynne, C. D. L. (2014). Behavioral differences among breeds of domestic dogs (Canis lupus familiaris): Current status of the science. Applied Animal Behavior Science, 155, 12-27.

Nelson, R. J. (2005). Introduction to behavioral endocrinology (3rd ed.). Sunderland: Sinauer.

Olioff, M., \& Stewart, J. (1978). Sex differences in the play behavior of prepubescent rats. Physiology \& Behavior, 20, 113-115.

Palagi, E. (2007). Play at work: Revisiting data focusing on chimpanzees (Pan troglodytes). Journal of Anthropological Sciences, 85, 63-81.

Pellis, S. M. (1991). How motivationally distinct is play? A preliminary case study. Animal Behaviour, 42, 851-853.

Pellis, S. M., \& Iwaniuk, A. N. (2004). Evolving a playful brain: A levels of control approach. International Journal of Comparative Psychology, 17, 92-118.

Pellis, S. M., \& Pellis, V. C. (1996). On knowing it's only play: The role of play signals in play fighting. Aggression and Violent Behavior, 1, 249-268.

Pellis, S. M., Pellis, V. C., \& Kolb, B. (1992). Neonatal testosterone augmentation increases juvenile play fighting but does not influence adult dominance relationships in male rats. Aggressive Behavior, 18, 437-447.

Pullen, A. J., (2011). Behavioural indicators of candidate enrichments for kennel housed dogs (Doctoral dissertation, University of Bristol). Retrieved from http://ethos.bl.uk/OrderDetails.do?uin=uk.bl.ethos. 535234

Rooney, N. J., Bradshaw, J. W. S., \& Robinson, I. H. (2000). A comparison of dog-dog and dog-human play behavior. Applied Animal Behavior Science, 66, 235-248.

Rooney, N. J., Bradshaw, J. W. S., \& Robinson, I. H. (2001). Do dogs respond to play signals given by humans? Animal Behavior, 61, $715-722$.

Russell, E. S. (1936). Playing with a dog. The Quarterly Review of Biology, 11, 1-15.

Siviy, S. M. (2016). A brain motivated to play: Insights into the neurobiology of playfulness. Behaviour, 153, 819-844.

Smith, P. K. (1982). Does play matter? Functional and evolutionary aspects of animal and human play. Behavioral and Brain Sciences, 5, 139-184.

Smith, L. K., Fantella, S.-L. N., \& Pellis, S. M. (1999). Playful defensive responses in adult male rats depend on the status of the unfamiliar opponent. Aggressive Behavior, 25, 141-152.

Tinbergen, N. (1963). On aims and methods of ethology. Zeitschrift fur Tierpsychologie, 20, 410-433.

Udell, M. A. R., Dorey, N. R., \& Wynne, C. D. L. (2011). Can your dog read your mind? Understanding the causes of canine perspective taking. Learning \& Behavior, 39, 289-302. doi:10.3758/s13420011-0034-6

Udell, M. A. R., Ewald, M., Dorey, N. R., \& Wynne, C. D. L. (2014). Exploring breed differences in dogs (Canis lupus familiaris): Does exaggeration or inhibition of predatory response predict performance on human-guided tasks? Animal Behavior, 89, 99-105.

Vanderschuren, L. J. M. J., Acterberg, E. J. M., \& Trezza, V. (2016). The neurobiology of social play and its rewarding value in rats. Neuroscience \& Biobehavioral Reviews, 70, 86-105.

Ward, C., Bauer, E. B., \& Smuts, B. B. (2008). Partner preferences and asymmetries in social play among domestic dog, Canis lupus familiaris, littermates. Animal Behavior, 76, 1187-1199. 